\title{
ESTATUTO FILIATIVO Y PRINCIPIOS CONSTITUCIONALES
}

\author{
PABlo Cornejo Aguilera* \\ Universidad de Chile
}

\begin{abstract}
RESUMEN: El presente trabajo pretende realizar un análisis crítico del actual Estatuto Filiativo chileno, buscando determinar en qué medida el legislador ha dado cumplimiento a los deberes impuestos por la faz estática de los derechos fundamentales de igualdad, identidad e interés superior del niño, esto es, en cuanto valores constitucionales que deben ser reconocidos y promovidos por todo el ordenamiento, para cuyos efectos se desarrollarán las consecuencias normativas que presenta el reconocimiento del derecho a la identidad biológica. Con todo, el presente trabajo supone que el legislador ante situaciones concretas, donde se vean enfrentados dos o más derechos fundamentales, cuenta con una relativa libertad de configuración destinada a conjugar los valores en oposición. De esta forma, el análisis que sigue no se limitará a la constatación de posibles antinomias, sino que por el contrario, en caso de advertir alguna institución contraria a alguno de los principios señalados, se centrará en su posible justificación desde la perspectiva de otros derechos fundamentales o valores constitucionales.
\end{abstract}

Palabras clave: Constitucionalización, filiación, igualdad, identidad, interés superior del niño.

ABSTRACT: The objective of this paper is to analyze the Chilean Affiliation Statute and determine to what extent the legislature has complied with imposed obligations by fundamental rights of equality, identity, and the superior interest for the child. The paper focuses on the normative consequences of recongnizing the right to biological identity according to constitucional values of the Chilean legal system. However, it is assumed that the legislature, facing situations where two or more fundamental rights are in opposition, has the freedom to combine opposing values. As a result, the following analysis surpasses the subject of conflict of laws, instead it provides constitutional or fundamental right justification's to institutions that goes against the aforementioned principles.

Key words: Constitutionalization, affliation, equality, identity, superior interest for the child.

\section{INTRODUCCIÓN}

Con la entrada en vigencia de la Ley 19.585 el Código Civil sufrió su mayor modificación desde que fuese promulgado en 1855, circunstancia que no debiese extrañarnos, si consideramos que, por su propio contenido, el Derecho de Familia es el área del Derecho Privado más propensa a sufrir presiones como consecuencia del cambio de las convicciones sociales, cuestión que ha resultado especialmente intensa en lo concerniente al concepto tradicional de familia construido en torno al matrimonio, a la estructura jerárquica que subyace a esta concepción y a las distinciones que existían entre las diversas categorías de hijos, donde el tipo de filiación quedaba determinado por la licitud o ilicitud de la conducta sexual de sus progenitores ${ }^{1}$.

\footnotetext{
Licenciado en Ciencias Jurídicas y Sociales, Universidad de Chile. Ayudante Departamento de Derecho Privado, Facultad de Derecho Universidad de Chile. Correo electrónico pablo_cornejo_aguilera@yahoo.es

1 En este sentido BARROS, quien, haciendo referencia a los cambios en materia de filiación, explica este fenómeno señalando que "en parte ello es el resultado de cambios en las costumbres; pero también lo es de un cambio muy universal en la cultura jurídica,
} 
Sin embargo, la justificación de estas reformas no se agota con la referencia a los cambios sociales experimentados durante el transcurso de este siglo. Por el contrario, en forma paralela a este proceso se ha producido el denominado fenómeno de constitucionalización del Derecho Privado, que impone una redefinición del concepto mismo de persona que subyace a esta regulación ${ }^{2}$, y se ha expresado plenamente en el desarrollo de la dogmática de los derechos de la personalidad, la cual nos proporciona un parámetro que permite cuestionar las instituciones de nuestro ordenamiento a fin de determinar si estas afectan la dignidad intrínseca del ser humano.

De esta forma, con la Reforma introducida por la Ley No 19.585 el legislador actualizó la regulación de la filiación, adecuándola con los nuevos paradigmas del Derecho de Familia, a la vez que solucionó las antinomias que se constataban al contrastar la regulación civil con las normas constitucionales, sujetándolas a los imperativos comprendidos en los principios de igualdad, de identidad y del interés superior del niño. Precisamente, transcurridos 10 años desde la mentada reforma, realizaremos un análisis de sus instituciones, verificando el grado de cumplimiento de los deberes impuestos por estos principios, a la vez que trataremos de determinar, en caso de existir contradicción, si esta es o no justificable en miras a otros principios o valores de orden constitucional.

Ahora bien, por la propia vigencia del derecho a la identidad resulta relevante examinar de qué manera se recogen y protegen los vínculos biológicos al momento de establecerse por la ley los hechos que definen la filiación. En este sentido, bien podría argumentarse que no se afecta este derecho si la legislación, pese a no contemplar los factores biológicos para determinar la filiación, establece mecanismos suficientes para que las personas conozcan cuál es su origen. Diferimos de esta apreciación. En nuestro concepto, tratándose la identidad biológica de un valor reconocido en nuestro sistema constitucional, se impone al legislador la necesidad de tenerlo en consideración al momento de definir cuáles serán las reglas para definir los

en la manera de mirar el rol del derecho en una sociedad plural, que reconoce ámbitos crecientes de autonomía y legitima desde el punto de vista jurídico diversas formas de vida. Frente a ese nuevo universalismo (individualista, igualitario, atento al débil) ha tendido a ceder la tradición canónica del derecho de familia, que perseguía expresar en reglas de derecho un concepto normativo, que prescribiera como debe estar constituida la familia". BARROS BOURIE, Enrique. "Notas Históricas y Comparadas sobre el Nuevo Ordenamiento Legal de la Filiación”. En: FundaCión FACUlTAD DE DERECHO, El Nuevo Estatuto de Filiación en el Código Civil Chileno. Santiago, Chile: LOM Ediciones, 1998, p. 41. Por su parte Méndez Costa, siguiendo a Savatier, señala que los datos que ofrece el desenvolvimiento de la sociedad en el último siglo y que han contribuido a la equiparación de las filiaciones son la declinación del patrimonio familiar y el cambio de actitud hacia el hijo. MÉNDEZ CostA, María Josefa. La Filiación. Santa Fe, Argentina: Rubinzal y Culzoni Editores, 1986, pp. 23-24.

2 En este sentido el profesor PEÑA, quien, refiriéndose a este fenómeno, explica que mientras el concepto de persona que subyace al Derecho Privado de la Codificación es el de sujeto capaz de cambio, construcción erigida en derredor de la propiedad y el intercambio, el Derecho Privado actual asimila la nueva concepción de persona desarrollada a partir de los textos constitucionales, toda vez que la generalización del lenguaje de los derechos da origen a la noción de derechos de la personalidad, entendidos como derechos subjetivos de carácter moral. PeÑa GonZÁlez, Carlos. El Derecho Civil en su relación con el Derecho Internacional de los Derechos Humanos. En: Medina, Cecilia, et al. Sistema Jurídico y Derechos Humanos. Santiago, Chile: Cuadernos de Análisis Jurídico Universidad Diego Portales, 1996. pp. 553-554. 
vínculos filiativos, debiendo correlativamente asumir la carga argumentativa de justificar la decisión de alejarse de este principio a fin de promover otro principio o valor constitucional ${ }^{3}$. A su vez, estas mismas consideraciones nos permiten realizar un análisis de la vigencia del respeto de este principio en la legislación chilena, así como de la justificación de su ruptura.

\section{EL DERECHO A LA IDENTIDAD BIOLÓGICA Y LA LEGISLACIÓN CIVIL EN MATERIA DE FILIACIÓN}

Siguiendo a Veloso entendemos por filiación "el vínculo jurídico que existe entre dos personas, una de las cuales se ha designado jurídicamente como padre o madre de la otra" ${ }^{4}$. Como se puede apreciar, resulta manifiesto que la filiación, vínculo jurídico, bien puede no coincidir con la realidad biológica, situación que lleva a Blasco Gascó a afirmar correctamente que "los conceptos de padre y madre e hijo no son conceptos naturales sino culturales (...) el concepto natural es el de progenitor y procreado" 5 de manera que "ser padre e hijo no es una realidad biológica sino una realidad jurídica que normalmente se basa en el hecho natural (ahora jurídico) de la generación" 6 .

Esta situación se refleja en nuestro actual sistema, donde existen personas que pueden no tener su filiación determinada, lo cual no obsta a que necesariamente tengan progenitores. Ahora bien, pese a que la filiación como vínculo jurídico se sitúa en un plano distinto a la procreación, debe en principio existir una correlación entre ellas, imponiéndose al legislador reconocer la importancia de estos nexos biológicos como consecuencia de su vinculación al principio de la identidad, lo cual implica que la filiación no puede ser derivada de cualquier hecho. En este sentido, podemos decir que el propio derecho a la identidad impone que la filiación deba construirse, en principio, sobre una concepción de tipo realista ${ }^{7}$, que ponga es-

\footnotetext{
3 Sobre este punto la Sentencia de la Sala Primera de 6 de mayo de 1997 señala que "La manera como los órganos estatales cumplen su deber de protección, es una decisión que cae dentro de su propia responsabilidad. Esto es válido en principio, no solo para los casos en los cuales existen diferentes posibilidades de brindar la protección que exige la Ley Fundamental [...] El Tribunal Constitucional Federal ha resaltado, por tanto, en jurisprudencia reiterada, que el establecimiento y la modificación normativa de un concepto de protección es asunto del legislador, al que en principio se le atribuye un espacio de evaluación, valoración y configuración, cuando se encuentre obligado a tomar medidas para la protección de un bien jurídico [...] Solo en forma excepcional se pueden derivar de los derechos fundamentales deberes de reglamentación concretos. Existe un espacio de configuración especialmente en aquellos casos en que hay que tener en cuenta derechos fundamentales que se contraponen entre sí". Citado en SCHWABE, Jurgen (comp.) Cincuenta Años de Jurisprudencia del Tribunal Constitucional Federal Alemán. Bogotá, Colombia: Ediciones Jurídicas Gustavo Ibáñez. 2003. pp. 33-34.

4 Veloso Valenzuela, Paulina y SCHMidt, Claudia. La Filiación en el nuevo Derecho de Familia. Santiago, Chile: Editorial LexisNexis, 2001, p. 81.

5 Blasco Gascó, F. En: A. M López y López, et al. Derecho de Familia -3a Edición- Valencia, España: Editorial Tirant Lo Blanch, 1997, pp. 281- 282.

6 Ibid., p. 282. En similar sentido v. AbELIUK, para quien la filiación es en principio siempre un hecho natural, ya que "todo hijo proviene de un padre y una de una madre, pero jurídicamente [...] no siempre habrá coincidencia”. ABELIUK MANASEVIC, René. La Filiación y sus Efectos. Santiago, Chile: Editorial Jurídica de Chile, 2001, p. 39.

7 Veloso Valenzuela, Paulina y SCHMidt, Claudia. op. cit. (n. 4), p. 83.
} 
pecial énfasis en el valor constitucional que se afirma al consagrar el derecho de toda persona a conocer su origen y nexo biológico.

Esta situación ha sido reconocida en Chile, donde el derecho a la identidad biológica es uno de los criterios seguidos para la determinación de los vínculos filiativos, situación especialmente resguardada cuando se trata de la determinación de la maternidad ${ }^{8}$. Por el contrario, en lo que respecta a la determinación de la paternidad, será necesario diferenciar cuál es el medio que está operando con objeto de poder determinar la efectiva relevancia que se reconoce a este principio. A fin de proceder a nuestro análisis, utilizaremos la distinción de Kemelmajer entre medios legales, voluntarios y judiciales de determinación de la filiación?

\subsection{DETERMINACIÓN LEGAL DE LA PATERNIDAD}

En el Derecho Nacional la determinación legal de la paternidad se expresa en la presunción pater is est, según la cual se reputarán hijos del marido aquellos nacidos existiendo matrimonio entre los cónyuges, durante su vigencia ${ }^{10}$, cuando se encuentre determinada la maternidad respecto de la mujer. Como se puede apreciar, se trata propiamente de una presunción, donde el legislador, a partir de ciertos hechos conocidos, como son el matrimonio, el momento del nacimiento y la filiación determinada respecto de la madre, infiere un hecho desconocido, como es la paternidad, la cual opera de pleno derecho y tiene un carácter simplemente legal, admitiendo ser desvirtuada por medio del ejercicio de las correspondientes vías procesales.

Como es fácil de advertir, nada asegura que exista realmente un vínculo biológico entre el padre y el hijo, de forma que cabe preguntarse si esta regulación violenta el derecho a la identidad biológica. En principio nuestra respuesta debe ser negativa: el Derecho opera en esta materia sobre la base de presunciones, principalmente, por que es posible suponer que en el contexto del matrimonio existió una cohabitación sexual entre los cónyuges, y que esta respetó el deber de fidelidad que lo caracteriza, de manera que resulta altamente probable que el hijo nacido fuera fruto de la relación entre los cónyuges.

De esta manera, la presunción pater is est operaría sobre la base de un criterio de normalidad, según el cual los hijos que nacen en el matrimonio usualmente son del marido,

\footnotetext{
8 v. artículo 183 CC, determinación legal de la maternidad. Con todo, se suscitarán conflictos cuando falte alguno de los hechos que configuran los supuestos fácticos de aplicación del artículo 183 CCch, caso en el que no quedará determinada la filiación del hijo respecto de la madre, teniendo aplicación todo lo que se desarrolle a propósito de las vías judiciales y negocial de determinación de la filiación.

9 Kemelmajer De Carlucci, Aída. "Lineamientos del Régimen de Filiación Biológica en Argentina y en la Reciente Reforma al Código Civil chileno”. En: Fundación Facultad De Derecho Universidad De Chile. El Nuevo Estatuto de Filiación en el Código Civil Chileno. Santiago, Chile: LOM Ediciones, 1998, p. 111.

10 Salvo excepciones del artículo 184 CCch.
} 
constituyendo una regla que importa un gran beneficio social, toda vez que satisface a bajo costo el interés en que no existan personas sin su filiación determinada y permite omitir la realización de otras medidas destinadas a asegurar que el marido tenga efectivamente un vínculo biológico con el hijo, como ocurre con las pericias biológicas. Sin embargo, todos estos beneficios sociales nos parecen secundarios si se afectara el interés del niño. Por esta razón, consideramos que la mayor justificación que recibe esta presunción se encuentra en el propio interés que tiene el hijo de ver establecida sin dilaciones su filiación, respecto de aquella persona a quien el sentido común y la forma habitual en que ocurren las cosas nos señala, muy probablemente, como su progenitor.

Con todo, los mismos argumentos expuestos y el efectivo respeto por el derecho a la identidad biológica imponen un límite a la aplicación de la presunción, como es la posible impugnación de la filiación establecida. En este sentido, consideramos que una privación de esta facultad necesariamente supone que el legislador, antes que establecer el vínculo conforme a un criterio de normalidad estaría privilegiando una opción pública en orden a resguardar la estabilidad de las familias por sobre el derecho a conocer los orígenes biológicos, negando el derecho a la identidad. Afortunadamente, nuestro ordenamiento actual no se encuentra afecto a esta crítica.

Ahora bien, frente a la presunción pater is est el legislador consagró una acción de desconocimiento, confiriendo legitimación activa para su ejercicio, al marido cuyo hijo ha nacido antes de los 180 días siguientes al matrimonio, en circunstancias que ha desconocido el hecho de la preñez (art. 180 inc. 20 CCch). Explicando esta regla, López afirma que se trata de un caso en que no deja de operar la presunción, sino que se otorga al marido una acción destinada a destruirla, en la medida que con posterioridad al nacimiento del hijo no lo hubiere reconocido por medio de actos positivos ${ }^{11}$. Por esta razón, el padre que ejerza esta acción solo deberá probar que el hijo nació dentro de los primeros 180 días del matrimonio, aun cuando efectivamente sea el progenitor, cuestión que permite explicar por qué el hijo podrá, en el futuro, reclamar su filiación respecto del padre que en su momento lo desconoció.

Por estas razones, López considera que se trata de una acción sin fundamento real que deshace el sistema filiativo, al basarse en el nacimiento del hijo antes de cumplido determinado término y no en la inexistencia del nexo biológico, llegando incluso al extremo de impedir al hijo exceptuarse en el fondo, acreditando la existencia de este ${ }^{12}$. Concordamos en gran medida con sus críticas. La única justificación que podemos pensar es la destrucción de las bases sobre las cuales se construye el criterio de normalidad, conforme al cual los hijos nacidos dentro del matrimonio son del marido. Sin embargo, aun en este caso la posibilidad de des-

\footnotetext{
11 López Rivera, Gisella. Nuevo Estatuto de Filiación y los Derechos Esenciales. Santiago, Chile: Editorial Jurídica ConoSur, 2001, p. 142 .

12 Ibid., p. 198.
} 
truir la presunción (y con ello la relación de filiación) por medio del simple desconocimiento, sin atender a la verdad biológica, resulta atentatorio contra la identidad del hijo y su interés en tener una relación filial determinada. Inclusive, existen razones para argumentar adicionalmente la existencia de una afectación al principio de igualdad, atendiendo que la opción conferida al padre en razón de la fecha de nacimiento del hijo crea una odiosa discriminación entre los diversos hijos que han nacido dentro del matrimonio, la cual solo podría fundamentarse como consecuencia de una discutible opción legislativa en orden a considerar que la concepción prematrimonial del hijo no ocurrió en el marco de una relación de pareja exclusiva, todo lo cual redunda en un resguardo desmesurado del interés del padre y de la formalidad del matrimonio en desmedro de los intereses del hijo. Por estas razones consideramos que esta acción resulta contraria a las bases sobre las cuales se construye el nuevo sistema.

En definitiva, consideramos que la determinación legal de la paternidad respeta el derecho a la identidad biológica del niño y resguarda su interés, por descansar sobre un vínculo biológico que puede darse por supuesto, atendidas las circunstancias fácticas consideradas para construir la presunción, al tiempo que contempla mecanismos para destruir esa presunción y hacer prevalecer la verdad biológica. Sin embargo, esta justificación no puede afirmarse respecto a la acción de desconocimiento, la cual parece contraria a los intereses constitucionales protegidos.

\subsection{DETERMINACIÓN NEGOCIAL DE LA FILIACIÓN}

La determinación negocial de la filiación en el Derecho Nacional opera a través del reconocimiento, acto jurídico voluntario; unilateral; personalísimo; irrevocable; puro y simple $^{13}$, por medio del cual una persona se declara padre de otra, estableciéndose un vínculo filiativo. Como medio de determinación de la filiación es subsidiario, toda vez que solo puede operar cuando no haya operado otro medio.

Este mecanismo presenta indiscutiblemente ciertas ventajas de orden práctico, sobre todo comparado con la acción de reclamación, desde el momento que basta para que desarrolle sus efectos la sola existencia de una declaración de voluntad, sin que sea necesario realizar alguna actividad de acreditación, cuestión que favorece la determinación de la filiación y reduce los costos sociales que implica el funcionamiento de los órganos jurisdiccionales ${ }^{14}$.

\footnotetext{
13 Ibid., p. 150-151.

14 En este sentido, Hernández Paulsen, Gabriel. "Críticas a la Regulación del Reconocimiento de Paternidad o Maternidad del Menor de Edad en el Código Civil Chileno". En: Estudios de Derecho Civil IV. Varios Autores, pp. 128-129. Santiago, Chile: Editorial Legal Publishing, 2009. TAPIA RodrígueZ, Mauricio. Los Proyectos de Reforma al Código Civil en Materia de Reconocimiento Voluntario. <En línea> [Citado 15 agosto 2010]. Disponible en World Wide Web: <http://www.microjuris.cl/ getContent?reference=MJCH_MJD296\&links=[PROYECT,\%20REFORM,\%20CODIG,\%20CIVIL,\%20MAT,\%20RECONOC, $\% 20$ VOLUNTAR]>
} 
Sin embargo, esta ventaja social resultará ser, en nuestro concepto, su principal inconveniente frente al respeto por los intereses constitucionales, toda vez que el reconocimiento puede perfectamente no relacionarse con un vínculo biológico o ni siquiera tener sustento en una situación sociofamiliar ${ }^{15}$.

En efecto, el legislador, al regular el reconocimiento en los artículos 187 a 190 CC, no estableció ningún resguardo para asegurar la correlación entre la filiación que se está reconociendo y la verdad biológica, pudiendo incluso pensarse el caso absurdo, en que una persona reconozca como hijo a otra no teniendo la diferencia de edad necesaria para ser su progenitor. Ahora bien, si bien puede afirmarse que este acto adolecerá de una serie de vicios $(v . g r$. seriedad de la declaración, objeto ilícito, causa ilícita), lo cierto es que esa nulidad deberá ser declarada judicialmente, al igual como ocurre con la eventual acción de impugnación.

De esta forma, nos encontramos frente a un medio que puede prescindir por completo de la realidad biológica, donde a diferencia de la presunción pater is est, no existen hechos que permitan establecer en principio la existencia del vínculo, cuestión que no se condice con el respeto de los valores aceptados al consagrar el derecho a la identidad, por más que sean procedentes acciones de impugnación y de nulidad ${ }^{16}$.

La otra institución negocial relacionada con la determinación de la filiación es el repudio, "acto unilateral y personalísimo, por medio del cual quien ha sido reconocido rechaza el reconocimiento, en el plazo legal" 17 . Nuevamente, como bien señala Veloso, no se requiere realizar actividad de acreditación alguna, pudiendo incluso el hijo repudiar a quien es su verdadero padre o madre ${ }^{18}$.

Se ha intentado justificar esta institución aduciendo que constituye una solución frente a la ausencia de limitaciones y requisitos de consentimiento del reconocimiento, o que se tra-

\footnotetext{
15 En este sentido Lathrop Gómez, Fabiola. "Reconocimiento de Paternidad de Hijos de Filiación No Matrimonial”, en: Gaceta Jurídica. $\mathrm{N}^{\circ} 343$, Santiago, p. 7. Adicionalmente, la autora identifica en estos reconocimientos una potencial afectación del derecho a la intimidad de la madre y del hijo, del derecho a la honra de la progenitora, y del interés superior del niño, que puede ver alterado su entorno familiar y social producto de este reconocimiento. Por su parte, el profesor HERNÁNDEZ, además de hacer referencia a los valores identificados precedentemente, señala que la imposición de nuevos requisitos para efectuar el reconocimiento no solo afecta al hijo en cuanto dificulta el establecimiento de un vínculo de filiación, sino que además puede afectar el derecho del progenitor reconociente a formar una familia y al libre desarrollo de su personalidad. HERNÁNDEZ PAULSEN, Gabriel. op. cit. (n. 14), pp. 126-127.

16 Una solución que conjuga bien los diversos intereses comprometidos en esta problemática es propuesta por HERNÁNDEZ quien, basándose en las estadísticas sobre la época de la vida del niño en que se produce el reconocimiento y la importancia que tiene la primera socialización del niño con su entorno más cercano, plantea conservar un régimen libre de reconocimiento hasta los dos años, término después del cual el reconocimiento solo podría producirse si interviene el reconocimiento de la madre. HeRnÁndeZ PAulsen, Gabriel. op. cit. (n. 14), pp. 134-138. Por su parte, el profesor TAPIA propone solucionar este conflicto reforzando aún más el mecanismo correctivo del repudio, negándole su característica de acto personalísimo, a fin que sea puede ser realizado válidamente por el representante legal del hijo antes que este alcance la mayoría de edad. Sin cuestionar el innegable sentido práctico que tiene esta segunda solución propuesta, consideramos que puede tratarse de una solución criticable desde la perspectiva de los valores que debe promover el legislador. TAPIA RODRÍGUEZ, Mauricio. op. cit. (n. 14).

17 Veloso Valenzuela, Paulina y SCHMidt, Claudia. op. cit. (n. 4), p. 119

18 Ibid.
} 
taría de una forma de evitar el reconocimiento motivado por algún interés ${ }^{19}$; y en la misma medida, ha recibido profundas críticas, concernientes a la afectación del derecho a la identidad, desde el momento que otorga un derecho absoluto al hijo impidiendo que predomine la verdad real, cuestión agravada si consideramos que se impide toda prueba del nexo biológico a fin de oponerse al repudio ${ }^{20}$.

Sin embargo, contrariamente a lo expuesto respecto del reconocimiento, nuestra postura frente el repudio difiere de las señaladas, en el entendido que se trata de una institución cuya justificación excede el constituir un mero mecanismo correctivo de los defectos presentes en el reconocimiento. En este sentido, si bien reconocemos que el repudio puede ser inconsistente con exigencias derivadas del derecho a la identidad biológica, no lo consideramos contrario per se al derecho a la identidad, atendido el estatus negativo y la faz dinámica que éste presenta ${ }^{21}$, los cuales nos permiten justificarlo como un resguardo que permitirá a una persona mantener su biografía personal sin alteraciones, excluyendo la nueva información relativa a su identidad biológica y sus vínculos filiativos, todo lo cual estará en definitiva destinado a poder conservar la situación que ha proyectado socialmente hasta ese momento y que consiste en no tener un vínculo biológico definido ni una filiación determinada.

Estas mismas consideraciones permiten, adicionalmente, construir una segunda justificación para esta institución, desde los valores comprendidos dentro de la autonomía personal, principio conforme al cual las personas son autoras de sus propias vidas ${ }^{22}$, permitiendo justificar la decisión de quien repudia como una opción destinada a excluir a ese progenitor del plan de vida formado.

En definitiva, consideramos que el ordenamiento, al proteger de manera integral a la persona, puede obviar la existencia de estos vínculos biológicos ${ }^{23}$ cuando ello se encuentre

\footnotetext{
19 Esta es al parecer la razón que prevaleció en la discusión del Senado, según la cita incorporada por LÓpEZ en su texto "La comisión manifestó su preocupación por la eventualidad de que el reconocimiento sea interesado -para reclamar posteriormente alimentos o eventualmente derechos sucesorios-, que el hijo no lo desee o que incluso perjudique al hijo, sobre todo considerando que el Código no establece requisitos destinados a cautelar su verosimilitud -como la diferencia de edad entre quien ejecuta este acto y la persona que se reconoce como hijo-, ni fija una época para efectuarlo, por lo que puede reconocerse a un hijo mayor de edad”. López RiverA, Gisella, op. cit. (n. 11), p. 154.

20 Ibid., p. 198.

21 Esta idea ha sido desarrollada respecto de la filiación adoptiva por ZANONNI. v. ZANNONI, Eduardo A. Adopción Plena y Derecho a la Identidad Personal. En: Kemelmajer De Carlucci, Aída, et al. La Verdad Biológica: ¿Nuevo Paradigma en el Derecho de Familia? El Derecho de Familia y los Nuevos Paradigmas. Tomo I. Buenos Aires, Argentina: Rubinzal-Culzoni Editores, 1998, p. 233. 22 RAZ, Joseph. "Autonomía, Tolerancia y el Principio del Daño", en: Revista del Centro de Estudios Públicos, No 76, p. 93 Santiago, Chile: Centro de Estudios Públicos, 1999.

23 En contra FigUEROA, para quien "el derecho a la identidad personal lleva consigo, como es natural, una obligación correlativa [...] Si toda persona tiene derecho a que se respete su identidad personal, a seguir siendo quien es, nadie puede dejar de se él mismo". Figueroa YÁÑeZ, Gonzalo. Derecho Civil de la Persona. Del Genoma al Nacimiento. Santiago, Chile: Editorial Jurídica de Chile, 2001, pp. 266-267. Con todo, los ejemplos que proporciona de obligaciones derivadas del derecho a la identidad se explican mejor como opciones de política criminal, en orden a favorecer la identificación y el funcionamiento de los mecanismos de persecución estatales.
} 
justificado por la protección de otros valores, acorde con la relativa libertad que tiene el legislador para ponderar los principios constitucionales enfrentados al momento de configurar las instituciones legales. En este caso, es el mismo interés de quien no quiere ver establecido a su respecto un vínculo de filiación, amparado en el derecho a la identidad y en su autonomía, lo que justifica que esta institución excluya el principio de la identidad biológica.

Una vez analizadas las principales instituciones que operan en la determinación negocial de la filiación, podemos concluir que en realidad el legislador se aparta en este punto de las orientaciones afirmadas por el principio de la identidad biológica, en una solución justificada tratándose del repudio. Diferente es nuestra opinión sobre el reconocimiento, toda vez que en este mecanismo lo que en definitiva primará serán consideraciones de índole social, como el interés en que las personas tengan establecida su filiación y los bajos costos que supone, no existiendo un interés real en la protección de la identidad del hijo, constituyendo adicionalmente una vía que facilita el fraude.

\subsection{DETERMINACIÓN JUDICIAL DE LA FILIACIÓN}

La determinación de la filiación a través de mecanismos judiciales nos inserta en la lógica del proceso, desde el momento que supone el ejercicio de las acciones de estado destinadas a determinar la existencia de un vínculo filiativo. Estas acciones, según señala Veloso, presentan la particularidad de vincularse con la esfera más intima del individuo ${ }^{24}$, a la vez que existe un interés público comprometido en su ejercicio.

Ahora bien, las acciones de impugnación y reclamación recogen el principio de la libre investigación de la paternidad (art. 195 CCch), lo que se condice con el derecho a la identidad biológica en su estatus positivo. Por esta razón, en principio, no existirían limitantes para la indagación de la existencia de un vínculo biológico que fundamente el establecimiento de la relación de filiación, con lo que la legislación nacional muestra un real avance respecto a la normativa anterior (Ley No 10.271), donde más que la búsqueda del vínculo biológico entre el padre y el hijo, lo que se pretendía era dar por establecida alguna manifestación de voluntad del padre en orden a reconocer al hijo natural.

Esta opción legislativa se confirma por la amplia admisibilidad de medios probatorios en el proceso de filiación (incluso antes de la entrada en vigencia de la Ley de Tribunales de Familia) y por el hecho de que se confiera una especial relevancia a las pericias biológicas, todo lo cual facilita la existencia de una efectiva correlación entre la verdad formal, que se establecerá en el proceso, y la verdad material; ponderación que se volverá a expresar en la excepción a la cosa juzgada que establece el art. 320 CCch, con lo que se refuerza la orientación general de protección al derecho a la identidad biológica.

24 Veloso Valenzuela, Paulina y Schmidt, Claudia, op. cit. (n. 4), p. 132. 
Conforme con lo señalado, podemos decir que en la determinación judicial de la filiación se respeta el derecho a la identidad biológica. Sin embargo, esa primera impresión debe ser moderada, toda vez que existen excepciones que han llevado a que ciertos autores se cuestionen realmente cuán determinante es la verdad biológica en la regulación del Código Civil. Estos puntos conflictivos, así como otras situaciones que no cuentan con solución expresa en la actual legislación y que han sido controvertidas en el Derecho Comparado, serán tratados a continuación.

\section{PROBLEMAS DE LA ACTUAL LEGISLACIÓN}

En esta parte trataremos cuatro situaciones que resultan conflictivas, especialmente desde el derecho a la identidad biológica, como son la posesión notoria del estado civil como prueba prevalente frente a la prueba pericial biológica; la ausencia de acciones para reclamar la filiación cuando se trata de una persona concebida mediante técnicas de reproducción asistida; la caducidad de la acción de reclamación; y un caso que no está solucionado expresamente en la actual legislación, referido a la negativa de la madre a entregar información para que el hijo pueda accionar a fin de determinar su filiación.

\subsection{LA POSESIÓN NOTORIA}

Siguiendo a Veloso podemos decir que "conceptualmente la posesión notoria constituye una especie de reconocimiento de hecho o social, de la paternidad o maternidad" 25 que es considerado en nuestro ordenamiento como un elemento de convicción que permite acreditar la filiación en juicio (art. 200 inciso $1^{\circ} \mathrm{CCch}$ ). En este sentido nos interesa destacar que, conforme a lo dispuesto en el artículo 201 CCch, el Juez enfrentado a una contradicción entre lo expresado por esta prueba y la verdad que resulte de las pruebas periciales biológicas, deberá preferir la posesión de estado, salvo que existan graves razones que demuestren la inconveniencia para el hijo de aplicar esta regla.

Como señala López, la solución recogida no corresponde a los lineamientos del Proyecto Original presentado por el Ejecutivo, donde la posesión notoria presentaba un carácter subsidiario, sirviendo "para determinar la filiación en caso de que no existiese prueba en contrario del nexo biológico" 26 . Por esta razón, la citada autora afirma que la "preponderancia de la verdad biológica, fue totalmente abortada por el Senado al darle consideración como un medio más de prueba, y no medio supletorio de prueba en el juicio de determinación.

\footnotetext{
Ibid., p. 168.

26 LÓpez Rivera, Gisella, op. cit. (n. 11), p. 165.
} 
Incluso, en caso de conflicto le llega a dar preponderancia a este" 27 de forma que "no se logró una de las ideas matrices del proyecto, cual era la de dar prioridad en la investigación de la filiación a la verdad biológica. Esto se denota de la sola lectura del texto, que concede a la apariencia jurídica (posesión notoria del estado civil) preferencia por sobre la verdad material"28. Todo lo expuesto conduce a López a cuestionarse la constitucionalidad de esta norma, considerándola en abierta contradicción con los artículos 7 y 8 de la Convención sobre los Derechos del Niño ${ }^{29}$.

En nuestro concepto, si bien resulta innegable que el legislador se aleja de la verdad biológica en la materia, creemos que no puede afirmarse simplemente su inconstitucionalidad como lo hace López, pudiendo justificarse la decisión legislativa en la medida que responda a un ejercicio de ponderación de valores constitucionales. Por esta razón, nuestra labor será identificar cuáles son los posibles valores constitucionales en pugna que justifican la opción legislativa.

Nos parece que la actual regulación puede justificarse en el propio interés superior del niño, desde el momento en que es posible interpretar esta disposición como una forma de protección del vínculo aparente, que en principio va en propio beneficio del niño, sobre todo si consideramos las consecuencias que tendrá el determinar una filiación diferente cuando ella no ha estado acompañada de una relación regular entre el padre y el hijo, como sí ocurre en el caso de la posesión ${ }^{30}$. Al respecto, concordamos con Barros, en el sentido de que "los lazos afectivos y psicológicos de paternidad se crean con más fortaleza en la vida diaria que en razón de la sola herencia, desprovista de toda otra relación filial"31.

Conforme a lo expuesto, podemos interpretar el artículo 201 CCch como una regla de razón que confiere una mayor valoración a la realidad que ha experimentado el niño y los lazos de familia que ha construido durante su vida, conciliando esta situación con las exigencias del caso concreto al atribuir al Juez la facultad de considerar las especiales circunstancias que pueden existir y que demuestren que el propio interés del niño se maximiza estableciendo el vínculo de filiación con su real progenitor, admitiendo en este caso que prevalezcan las pruebas de carácter biológico ${ }^{32}$.

27 Ibid., p. 165 .

28 Ibid., p. 166

29 Ibid., p. 167.

30 Con todo, esta argumentación debe ser desarrollada con cuidado, considerando siempre que se trata de un principio garantista, cuya interpretación en el caso concreto debe importar propiamente la maximización del bienestar material y espiritual del niño, tanto en el presente como en el futuro, de forma que en muchas oportunidades el resguardo de su identidad biológica será la mejor manera de velar por su interés superior. En este sentido Sentencia de 2 de noviembre de 2006. Corte Suprema. No Legal Publishing: 35511.

31 BARros Bourie, Enrique, op. cit. (n. 1), p. 52

32 Sobre este punto puede considerarse la traumática experiencia de las adopciones irregulares de hijos de mujeres detenidas desaparecidas durante la dictadura argentina. 
Ahora bien, por su fundamento la argumentación desarrollada solo será aplicable cuando se trate de un niño, no pudiendo extenderse a las personas mayores de 18 años. Con todo, consideramos que esta circunstancia no obsta a la justificación de la regla, la cual contará en este caso con una justificación aún más intensa, desde la perspectiva del resguardo de la autonomía personal y de la identidad que la persona ha construido durante su vida ${ }^{33}$, lo cual se expresa en el hecho que será la misma persona respecto de la cual se intente establecer un vínculo de filiación quien decida conservar sus actuales relaciones de familia, oponiendo como prueba contraria la posesión notoria.

Finalmente, deseamos terminar este apartado llamando la atención respecto de la extensión del derecho a la identidad. Contrariamente a lo señalado por algunos autores, creemos que esta disposición no puede ser criticada desde la perspectiva de la efectiva vigencia del derecho a la identidad, al menos no sin incurrir en un error, cual es considerar este derecho limitado a un aspecto de su faz estática, como es la identidad biológica. Por el contrario, el resguardo de la posesión notoria puede ser generalmente justificado desde el mismo derecho a la identidad, si nos atenemos a su faz dinámica, sentido en el cual concordamos plenamente con Zannoni, en orden a que "el concepto de identidad filiatoria como pura referencia a su presupuesto biológico no es suficiente para definir, por él mismo, la proyección dinámica de la identidad filiatoria" ${ }^{4}$, de forma que la posesión notoria constituye, en nuestro concepto, una protección de una situación de apariencia que ha permitido construir a la persona aquellos elementos que permiten definirla en su condición actual, como son sus vínculos afectivos primarios y sus relaciones de familia, impidiendo que esa situación fuere negada o desvirtuada por un tercero.

Recapitulando, no podemos considerar el artículo 201 CCch como una norma inconstitucional, en la medida que reconoce como fundamento la protección de otros valores constitucionales. Por el contrario, esta norma puede ser reinterpretada, como una forma de resguardo de la identidad en su faz dinámica, la cual, por estar fundada en la protección de los intereses del hijo en caso alguno puede servir para enervar las acciones por él intentadas, destinadas a reconocer sus verdaderos vínculos biológicos.

\subsection{FILIACIÓN EN LAS TÉCNICAS DE REPRODUCCIÓN ASISTIDA}

La regulación del artículo 182 CCch se encarga de definir quiénes son los padres del hijo concebido mediante la aplicación de estas técnicas, basándose en un elemento eminen-

\footnotetext{
33 Inclusive, podemos afirmar que el respeto por la autonomía privada de la persona mayor de edad impone necesariamente la ausencia de una regla de razón que permita al Juez preferir la prueba pericial, a diferencia de lo que ocurre con los niños. De esta forma, partiendo de la base que la persona mayor de edad es el mejor árbitro de su propio interés y no requiere de una guía para tomar sus decisiones vitales, el Juez no podrá invocar en contra de su decisión su propio interés a fin de hacer prevalecer el vínculo biológico, quedando sujeto a la prueba que ésta rinda en orden a acreditar la posesión notoria.

34 ZANnONI, Eduardo A, op. cit. (n. 21), p. 233.
} 
temente volitivo, como es la decisión de someterse a ella. En este sentido, como Gómez de la Torre señala, "el elemento determinante de la filiación es el consentimiento a someterse a estas técnicas, puesto que para someterse a ellas debe existir un consentimiento por parte del hombre para que a la mujer le practiquen las técnicas y de la mujer a someterse a ellas" 35 , de manera que "lo esencial de la procreación a través de estas técnicas, cuando hay donación de gametos o de embrión, se encuentra en la voluntad del que quiere ser y sentirse padre o madre a pesar de sus impedimentos o carencias fisiológicas" 36.

De esta manera, la regulación nacional comprendería el supuesto de utilización de material genético de un tercero, cuestión que necesariamente importa una falta de correlación biológica entre el hijo que nace y al menos uno de sus padres. Ahora bien, con el objeto de hacer frente a estas dificultades, a reglón seguido de definir quienes son padres del concebido por medio de estas técnicas, el legislador nacional establece la improcedencia de las acciones de filiación para alterar este vínculo. Frente a esta situación debemos cuestionarnos si esta prohibición absoluta resulta concordante con los imperativos de la identidad biológica.

En nuestro concepto, el legislador no podría establecer una solución diversa para determinar la filiación en estos casos, so riesgo de eliminar en la práctica una herramienta de comprobada utilidad para aquellas parejas que no pueden optar por la procreación natural ${ }^{37}$. Por esta razón, consideramos que el examen crítico no debe referirse estrictamente a la regla de determinación de la filiación, sino a la admisibilidad de las técnicas de reproducción humana asistida frente al derecho a la identidad del hijo. En principio, consideramos válida la decisión adoptada por el legislador, por considerar que en ella subyace una opción en orden a conferir un mayor valor al ejercicio de los derechos reproductivos de los padres, expresados en la decisión responsable de serlo y asumir los deberes que esta calidad importa; antes que a la existencia de un mero vínculo genético, cuestión que, como señalamos anteriormente, no determina la efectiva existencia de los vínculos afectivos y los deberes de mutua consideración que supone formar parte de una familia. De esta forma, consideramos que en la materia el legislador consideró correctamente qué hecho merece una mayor relevancia para efectos de establecer el vínculo jurídico de la filiación, primando en esta valoración la opción de ser padres por sobre la sola existencia de un vínculo genético.

35 Gómez de la Torre Vargas, Maricruz. "La Determinación de la Filiación y las Técnicas de Reproducción Humana Asistida”. En: Fundación Facultad de Derecho, Universidad De Chile. El Nuevo Estatuto de Filiación en el Código Civil Chileno. Santiago, Chile: LOM Ediciones, 1998, p. 198.

36 Ibid., p. 191.

37 Con todo, esta consideración social no puede servir de fundamento para la regla, si no considera los efectivos intereses del niño. En este sentido Turner SAElzer, Susan, et al. "Técnicas de Reproducción Humana Asistida. Una Perspectiva desde los Intereses del Hijo", en: Revista de Derecho Universidad Austral. Volumen 11, pp. 13-26. Valdivia, Chile: Universidad Austral de Chile, 2000. 
Sin embargo, no puede dejar de considerarse que la justificación expuesta solo dice relación con las reglas que determinan la filiación, de forma que no es posible derivar del artículo 182 CCch una proscripción absoluta de la búsqueda de la identidad biológica. Por el contrario, una interpretación como la señalada negaría el derecho a la identidad del concebido. Con todo, creemos que en estos eventuales conflictos deben existir razones adicionales que justifiquen la búsqueda de los orígenes biológicos, toda vez que revelar la identidad del tercero importaría una afectación de su derecho a la intimidad.

\subsection{CADUCIDAD DE La ACCIÓN DE RECLAMACIÓN}

El legislador confirió a la acción de reclamación el carácter de imprescriptible (art. 195 inciso $2^{\circ} \mathrm{CCch}$ ), pese a lo cual limita la posibilidad de ejercicio tratándose de hijos póstumos (art. 206 CCch) quienes solo podrán accionar contra los herederos de su progenitor dentro del plazo de 3 años, contados desde su muerte o desde la fecha en que hubiese adquirido plena capacidad. Esta regla, que limita la posibilidad de establecer el vínculo de filiación basada en la consolidación de las situaciones jurídicas, no cuenta con una interpretación pacífica, dado que mientras algunos autores afirman su excepcionalidad frente a la regla general consistente en la extinción de la acción de reclamación una vez muerto el progenitor ${ }^{38}$, la Jurisprudencia ha afirmado su excepcionalidad solo en cuanto establecería un plazo determinado para ejercer una acción, en desmedro del hijo póstumo ${ }^{39}$. Cualquiera sea la interpretación seguida, consideramos que esta regla de caducidad priva de protección a un interés esencial del hijo, como es su identidad, sin encontrarse justificada en fundamentos relacionados con la protección de otros intereses constitucionales.

En efecto, si consideramos como fundamento de esta regla la consolidación de las situaciones jurídicas, nos encontramos con que el legislador no solo persigue este fin a través de una afectación desproporcionada del derecho a la identidad, sino que además lo hace estableciendo una arbitraria distinción, desde el momento en que el interés de resguardar la estabilidad de situaciones jurídicas patrimoniales ya había sido considerado por el legislador mediante el establecimiento de reglas generales, como la contenida en el artículo 195 inciso $2^{\circ}$ CCch, disposición que, como contrapartida a la imprescriptibilidad de la acción de recla-

\footnotetext{
38 En este sentido Veloso, pese a cuestionar su validez. Veloso Valenzuela, Paulina y Schmidt, Claudia, op. cit. (n. 4), p. 133.

Ramos Pazos, René. Derecho de Familia. Tomo II. Santiago, Chile: Editorial Jurídica de Chile, 2005, pp. 397-400.

39 En éste sentido, Sentencia de 25 de enero de 2007, Corte de Apelaciones de Valdivia, comentada por TURNER. TURNER SAElzer, Susan. "Transmisibilidad y Disponibilidad de la Acción de Reclamación de Filiación. Sentencia sobre el Alcance de la Legitimación Pasiva de la Acción de Reclamación Intentada por el Hijo (Juzgado de Familia de Valdivia, Corte de Apelaciones de Valdivia)" en: Revista de Derecho. Universidad Austral, vol. 20, pp. 249-254. Chile: Universidad Austral de Chile, 2007. Sentencia de 14 de abril de 2008, Corte de Apelaciones de Valparaíso. No Legal Publishing: 39237. Sentencia de 21 de septiembre de 2006. Corte Suprema. No Legal Publishing: 35157.
} 
mación, sujeta los efectos patrimoniales de la filiación determinada a sus particulares reglas de prescripción. De esta forma, nos encontramos con que la discriminación establecida en el artículo 206 CCch carece de justificación, y resulta doblemente lesiva, desde el momento en que no solo afecta el derecho a la identidad, sino que lo hace discriminando a los hijos que reclamen su filiación con posterioridad a la muerte de su progenitor frente a los restantes hijos, quienes estarán sujetos a la regla general de estabilización de los efectos patrimoniales de la filiación contenida en el artículo 195 inciso $2^{\circ} \mathrm{CCch}$.

Con todo, es posible afirmar que gran parte de estas dificultades se han salvado a través de la interpretación restrictiva del artículo 206 Código Civil que han seguido nuestros Tribunales Superiores de Justicia. Sin embargo, esta interpretación trae aparejadas nuevas dificultades, desde el momento en que se construye atribuyendo al legislador la voluntad de establecer un régimen excepcional aplicable solamente respecto del hijo póstumo, situación que no guarda relación alguna con la protección del interés superior del niño, de la identidad biológica y de la igualdad. Por esta razón, si bien consideramos se trata de una interpretación que busca resguardar los intereses fundamentales del hijo, lo hace al costo de imponer una discriminación arbitraria respecto de una categoría de ellos, como es el póstumo.

Ahora bien, similares críticas se pueden formular respecto del artículo 207 CCch, que priva a los herederos del hijo fallecido de la facultad de reconstruir los vínculos que permiten definir su identidad personal, al establecer la caducidad de la acción en caso de no ejercerse dentro de los 3 años siguientes a su muerte, sin considerar factores como la disponibilidad de la información concerniente al vínculo biológico. Con todo, en este caso la opción legislativa se puede fundar en el menor interés que tendrán los herederos en ver establecida una relación filiativa que no les afectará directamente, interés que es considerado de menor valor que el resguardo de la privacidad familiar y que permitiría fundar una limitación temporal al ejercicio de la acción. Sin embargo, esta argumentación, que posibilitaría salvar las objeciones realizadas desde el principio de la identidad, permiten precisamente cuestionar la regulación desde la perspectiva de la igualdad, toda vez que, considerado el plazo de tres años dispuesto por el legislador, nos encontraremos usualmente en la práctica con que este se cumplirá incluso en forma previa al plazo de prescripción de las acciones patrimoniales que pueden ejercerse contra el progenitor del causante (cuestión que puede revestir extraordinaria importancia, si consideramos los efectos del derecho de representación) impidiendo definitivamente el establecimiento de un vínculo indispensable a fin de poder ejercer estas acciones.

Por estas razones, consideramos que la caducidad de la acción de reclamación constituye una afectación desproporcionada e innecesaria a los intereses protegidos por el derecho a la identidad, que niega la facultad de conocer un elemento integrante de la biografía personal, como es la identidad de los ancestros; al tiempo que importa en la práctica el establecimiento de un trato diferenciado perjudicial, que se aleja de la regla general establecida en el artículo 
195 inciso $2^{\circ}$ Código Civil, razones por las cuales consideramos necesaria su derogación de nuestro Estatuto Filiativo.

\subsection{NEGATIVA A PROPORCIONAR INFORMACIÓN RELEVANTE PARA LA DETERMINACIÓN DE LA FILIACIÓN}

Se trata de una situación que no cuenta con una regulación expresa en nuestro Código, donde existirá una colisión entre dos derechos fundamentales, cuales son el derecho de la madre o padre a mantener cierta esfera de su vida ajena a injerencias de terceros (intimidad) y el derecho que tiene el hijo a obtener información que le permita ejercer las acciones de reclamación respecto del otro progenitor (identidad).

En el Derecho Comparado destaca el caso de Alemania, país en el cual sus Tribunales, enfrentados a esta situación, han debido resolver el problema caso a caso, ponderando los respectivos intereses en colisión. De esta forma, en la Jurisprudencia civil ha existido una tendencia a conferir primacía al derecho a conocer sus orígenes por parte del hijo, en una interpretación fundada en el artículo $1618 \mathrm{a} \mathrm{BGB}^{40}$, disposición de carácter programático y supletorio que establece deberes generales aplicables a todas las relaciones filiales, resolviendo que a partir de ella puede derivarse un deber específico de la madre de prestar su ayuda al hijo ${ }^{41}$. En nuestro concepto, sin perjuicio de que la propia naturaleza de los intereses comprometidos impide otorgar una respuesta abstracta e invariable que omita la labor de ponderación, consideramos que una solución como la descrita es concordante con el Derecho Nacional.

Para poder fundamentar la aseveración realizada debemos, en primer lugar, considerar la guía que nos proporciona el interés superior del niño, sobre todo por la importancia que tendrá esta información para el desarrollo de su plena autonomía ${ }^{42}$. De esta forma, al igual

\footnotetext{
40 “Los padres y los hijos están recíprocamente obligados a prestarse asistencia y consideración”. EIRANOVA ENCINAS, Emilio. Código Civil Alemán Comentado. Barcelona, España: Marcial Pons, Ediciones Jurídicas y Sociales S.A., 1999, p. 479.

41 Turner S. SuSAN. "El Derecho a la Identidad como Derivación Constitucional. Análisis de la Jurisprudencia Constitucional Alemana”. En: Universidad Austral De Chile. La Constitucionalización del Derecho Chileno. Santiago, Chile: Editorial Jurídica de Chile, 2003, p. 133. Con todo, la ponderación realizada por el Tribunal de Familia fue invalidada en sede constitucional, donde se confirió primacía al derecho de la madre a conservar su esfera de intimidad. Ibid. p. 129. La sentencia puede ser consultada en SCHWABE, Jurgen, op. cit. (n. 3), p. 31-34.

42 En este sentido, parte de la doctrina argentina ha derivado a partir de la mencionada convención internacional la existencia de un deber de la madre de colaborar con la determinación de la filiación de su hijo, pudiendo destacarse lo señalado por BISCA$\mathrm{RO}$ en orden que "Creemos que frente al conflicto que intereses que plantea el derecho a la intimidad de la madre y el derecho del niño a conocer su identidad, debe prevalecer, sin lugar a dudas este último. El niño tiene derecho a tener un emplazamiento filial y los consiguientes derechos que emergen de este último. Estos derechos le son reconocidos por la Convención de los Derechos del Niño aprobada por nuestro país mediante la sanción de la ley 23.849", en una opinión que resulta coincidente con la expuesta por Molina y Viggiola, quienes señalan que "Sin embargo, para ser coherentes con el respeto al derecho de todo ser humano a conocer su origen, con las consecuencias que hemos señalado precedentemente, es necesario que la madre sea colaboradora activa de la satisfacción de este derecho personalísimo.[...] En el difícil conflicto entre los derechos personalísimos de elevada jerarquía como son el derecho a la intimidad de la madre y el derecho a la identidad del menor, nos pronunciamos por la prioridad del segundo, y son de aplicación las mismas consideraciones que hemos reseñado en el caso de conflictos entre el
} 
como lo hizo la Jurisprudencia civil alemana, podemos interpretar en forma progresiva el art. 222 inciso $2^{\circ} \mathrm{CC}$, norma que, en conformidad con los deberes impuestos por la Convención de Derechos del Niño, fija las bases sobre las cuales deben desarrollarse las relaciones parentofiliales en un Derecho que reconoce y promueve sus intereses, derivando a partir de él un deber concreto para la madre, quien en principio no podría escudarse en su derecho a la intimidad cuando de ello se derive una afectación a los intereses del menor.

Sin embargo esta argumentación es limitada por el propio contenido de la citada disposición, razón por la cual solo es posible construir un deber de estas características respecto de la madre cuando el beneficiario se trate de un niño, excluyendo todos aquellos casos en que quien requiera la información sea un mayor de edad. Con la finalidad de salvar esta dificultad se pueden considerar al menos dos argumentos.

El primero de ellos es de orden meramente gramatical, y se basa en el texto mismo de la disposición en comento, que en lugar de referirse al niño lo hace al hijo, por lo que, al menos literalmente, no existirían obstáculos para ampliar las conclusiones expuestas a estos restantes casos. Sin embargo, consideramos esta solución deficiente, toda vez que deja incólume un importante problema de fondo, cual es la posibilidad de argumentar la existencia de deberes de semejante intensidad, que impliquen la renuncia de una esfera personalísima tutelada por el ordenamiento, en las relaciones entre personas adultas. Por esta razón, y a pesar del sentido literal del artículo 222 CCch, consideramos que la existencia de este deber no puede construirse basándose en una disposición que desarrolla una guía que es funcional e instrumental al pleno desarrollo de la personalidad del hijo, como es el interés superior del niño, desde el momento que esta dejará de tener aplicación cuando desaparezca el sujeto protegido, como ocurrirá siempre que nos encontremos ante un conflicto que involucre a dos personas absolutamente autónomas, respecto de las cuales no sea posible afirmar la existencia de deberes especiales de protección; solución que se ve confirmada si consideramos que el hijo mayor de edad tiene similares deberes de respeto hacia los intereses personalísimos de sus padres.

Por estas razones consideramos que en estos casos la existencia de un deber especial de entregar información que facilite la determinación de los vínculos filiativos del hijo solamente podrá construirse en base a la responsabilidad que adquiere el progenitor por el hecho de la procreación. De esta forma, puede argumentarse que, en la medida que el padre o madre es responsable de la propia existencia del hijo y, al menos parcialmente, de que nunca pudiese conocer a su otro progenitor, debe imponerse prima facie sobre él o ella un deber de colaboración, a fin de evitar que recaigan sobre él las consecuencias lesivas de las actuaciones de un tercero.

derecho a la identidad y otros derechos personalísimos". BisCARO, Beatriz R. "Daños Derivados de la Falta de Reconocimiento del Hijo”. En: GHeRsI, Carlos (Coord.). Derecho de Daños. Buenos Aires, Argentina: Abeledo-Perrot, 1999, p. 441.

Molina Quiroga, Eduardo y Viggiola, Lidia E. "Derecho a la Identidad y no Reconocimiento del Hijo Extramatrimonial". En: GHERSI, Carlos (coord.), op. cit. (n. 42), p. 467.

Con todo, discrepamos del carácter absoluto de la solución propuesta por la doctrina citada. 
Finalmente, más allá de las razones expuestas, que permiten justificar prima facie la existencia de un deber de entregar información, hay que considerar las especiales circunstancias existentes en cada caso al momento de realizar la ponderación de los intereses comprometidos. En este sentido, se encontrarían con mayor razón justificados estos deberes cuando exista riesgo de afectación de otros derechos del hijo ( $v \cdot g r$. enfermedades congénitas) en tanto que podrá admitirse la renuencia de la madre en aquellas circunstancias donde la revelación de la identidad del otro progenitor implique una afectación de especial intensidad a su derecho a la intimidad ( $v . g r$. situaciones de abuso sexual), el sacrificio de intereses personalísimos anexos ( $v$. gr. integridad psíquica), o bien pueda vulnerar la prohibición de autoincriminación (v. gr. incesto consentido).

\section{REFERENCIAS BIBLIOGRÁFICAS}

Abeliuk Manasevic, René. La Filiación y sus Efectos. Santiago, Chile: Editorial Jurídica de Chile, 2001.

Barros Bourie, Enrique. "Notas Históricas y Comparadas sobre el Nuevo Ordenamiento Legal de la Filiación”. En: Fundación Facultad de Derecho, El Nuevo Estatuto de Filiación en el Código Civil Chileno. Santiago, Chile: LOM Ediciones, 1998.

Biscaro, Beatriz R. Daños Derivados de la Falta de Reconocimiento del Hijo En: Ghersi, Carlos (Coord.). Derecho de Daños. Buenos Aires, Argentina: Abeledo-Perrot, 1999.

Blasco Gascó, F. En: A. M López y López, et al. Derecho de Familia, 3a Edición, Valencia, España: Editorial Tirant Lo Blanch, 1997.

EIranova Encinas, Emilio. Código Civil Alemán Comentado. Barcelona, España: Marcial Pons, Ediciones Jurídicas y Sociales S.A., 1999.

Figueroa YÁÑez, Gonzalo. Derecho Civil de la Persona. Del Genoma al Nacimiento. Santiago, Chile: Editorial Jurídica de Chile, 2001.

GÓMEZ de la Torre VARgas, Maricruz. "La Determinación de la Filiación y las Técnicas de Reproducción Humana Asistida”. En: Fundación Facultad de Derecho, Universidad de Chile. El Nuevo Estatuto de Filiación en el Código Civil Chileno. Santiago, Chile: LOM Ediciones, 1998.

Hernández Paulsen, Gabriel. "Críticas a la Regulación del Reconocimiento de Paternidad o Maternidad del Menor de Edad en el Código Civil Chileno”. En: Estudios de Derecho Civil IV. Varios Autores, pp. 128129. Santiago, Chile: Editorial Legal Publishing, 2009.

Kemelmajer de Carlucci, Aída. "Lineamientos del Régimen de Filiación Biológica en Argentina y en la Reciente Reforma al Código Civil Chileno”. En: Fundación Facultad de Derecho Universidad de Chile. El Nuevo Estatuto de Filiación en el Código Civil Chileno. Santiago, Chile: LOM Ediciones, 1998.

Lathrop Gómez, Fabiola. "Reconocimiento de Paternidad de Hijos de Filiación No Matrimonial”, en: Gaceta Jurídica $\mathrm{N}^{\circ} 343$.

López RiverA, Gisella. Nuevo Estatuto de Filiación y los Derechos Esenciales. Santiago, Chile: Editorial Jurídica ConoSur, 2001.

MÉndez Costa, María Josefa. La Filiación. Santa Fe, Argentina: Rubinzal y Culzoni Editores, 1986.

Molina Quiroga, Eduardo y Viggiola, Lidia E. “Derecho a la Identidad y no Reconocimiento del Hijo Extramatrimonial”. En: Ghersi, Carlos (Coord.). Derecho de Daños. Buenos Aires, Argentina: Abeledo-Perrot, 1999. 
PeÑa GonzÁlez, Carlos. "El Derecho Civil en su relación con el Derecho Internacional de los Derechos Humanos". En: Medina, Cecilia, et al. Sistema Jurídico y Derechos Humanos. Santiago, Chile: Cuadernos de Análisis Jurídico Universidad Diego Portales.

Ramos Pazos, René. Derecho de Familia. Tomo II. Santiago, Chile: Editorial Jurídica de Chile, 2005.

RAZ, Joseph. "Autonomía, Tolerancia y el Principio del Daño", en: Revista del Centro de Estudios Públicos, No 76, Santiago, Chile: Centro de Estudios Públicos, 1999.

SCHWABE, Jurgen (comp.) Cincuenta Años de Jurisprudencia del Tribunal Constitucional Federal Alemán. Bogotá, Colombia: Ediciones Jurídicas Gustavo Ibáñez, 2003.

Tapia Rodríguez, Mauricio. Los Proyectos de Reforma al Código Civil en Materia de Reconocimiento Voluntario. Recurso electrónico <En línea> [Citado 15 agosto 2010]. Disponible en World Wide Web: http://www.microjuris.cl/getContent?reference=MJCH_MJD296\&links=[PROYECT,\%20REFORM,\%20CODIG,\%20CIVIL,\%20MAT,\%20RECONOC,\%20VOLUNTAR]

Turner Saelzer, Susan, et al. “Técnicas de Reproducción Humana Asistida. Una Perspectiva desde los Intereses del Hijo", en: Revista de Derecho. Universidad Austral. Volumen 11. Valdivia, Chile: Universidad Austral de Chile, 2000.

"El Derecho a la Identidad como Derivación Constitucional. Análisis de la Jurisprudencia Constitucional Alemana”. En: Universidad Austral De Chile. La Constitucionalización del Derecho Chileno. Santiago, Chile: Editorial Jurídica de Chile, 2003.

“Transmisibilidad y Disponibilidad de la Acción de Reclamación de Filiación. Sentencia sobre el Alcance de la Legitimación Pasiva de la Acción de Reclamación Intentada por el Hijo (Juzgado de Familia de Valdivia, Corte de Apelaciones de Valdivia)". En: Revista de Derecho. Universidad Austral. Volumen 20. Valdivia, Chile: Universidad Austral de Chile, 2007.

Veloso Valenzuela, Paulina y SCHMidt, Claudia. La Filiación en el nuevo Derecho de Familia. Santiago, Chile: Editorial LexisNexis, 2001. 